\section{Health in the laboratory}

FOR more than 20 years both government and unions have been concerned about standards of safety in British laboratories and the health of people working in them. The first major stimulus came in 1957 when D. D. Reid, of the London School of Hygiene and Tropical Medicine (LSHTM), reported that the incidence of tuberculosis among medical laboratory workers was higher than expected. As a result, a working party of the Public Health Laboratory Service (PHLS) made recommendations for safe working in laboratories handling tuberculous material. These were revised in 1968, but adverse reports continued to appear sporadically, and in 1970 the Department of Health and Social Security (DHSS) commissioned a full investigation from the Trades Union Congress (TUC) Centennial Institute of Occupational Health at LSHTM. This was carried out between 1971 and 1974 and the full report results appeared as a thesis in 1975. As far as the author is aware, the DHSS has done no more than file the report.

The investigation included retrospective surveys of the incidence of four infectious diseases and the standards of health care and safety in the laboratories of the National Health Service (NHS, consisting of hospital laboratories), the National Blood Transfusion Service and the PHLS (Harrington, J. M., \& Shannon, H. S. Brit. Med. J. 1, 759; 1976). The surveys involved 24,000 workers, constituting $85 \%$ of the total in those laboratories. The results for the infectious diseases are summarised in Table 1. land and Wales and in Scotland represented, respectively, a 5.4 and a 4.2 times greater risk of acquiring the disease among laboratory workers than the general population. It was not possible to make a similar assessment for the other infections, but the conclusion was that hepatitis possibly remained an occupational hazard for laboratory workers, while shigellosis may have been more prevalent among them than among the general populasafety training. tories.
The totals for tuberculosis in Eng-

tion. All four diseases seemed most likely to afflict technicians.

Variable standards of safety and health care were reported (Harrington, J. M. \& Shannon, H. S. Brit. med. J. 1, 626; 1977). Less than half of the laboratory workers had been examined medically before employment and a similarly small proportion had been offered vaccination. The length of service of the workers indicated that the standards had not improved during the previous 10 years and had probably deteriorated. Scottish laboratories proved to have a slightly better record in safety control than their English and Welsh counterparts, and PHLS laboratories did better than those of the NHS, providing more formal

Mouth pipetting was still being practised in $65 \%$ of English and Welsh laboratories and $28 \%$ of Scottish laboratories. Although protective clothing was usually available, its use was compulsory in only one third of English and Welsh laboratories and twothirds of Scottish laboratories, even when procedures involved were known to be hazardous. The servicing of safety cabinets was inadequate in twothirds of Scottish laboratories and $40 \%$ of English and Welsh laboratories, and known carcinogens were still being used in a small proportion of labora-

Another phase of the investigation involved a prospective survey of accidents and absence from work due to illness in $10 \%$ of the laboratories surveyed previously (Harrington, J. M. MD thesis Univ. London, 1975). Between April 1973 and March 1974 records were kept for 2,520 workers in 39 laboratories. Absence was generally lower than in other British industries. The only possible sign of a link with occupational hazards was provided by infectious and parasitic diseases, which constituted the chief cause of absence.

During this phase of the investigation 627 accidents caused injury in the 39 laboratories and one in four of the workers was affected. Technicians$64 \%$ of the population-suffered $76 \%$ of the injuries, including all nine of

Table 1 Infectious diseases in laboratory workers in England and Wales in 1971 and Scotland in 1973.

\begin{tabular}{lccccc}
\multicolumn{1}{c}{ Infection } & $\begin{array}{c}\text { Medical } \\
\text { staff }\end{array}$ & $\begin{array}{c}\text { Scientific } \\
\text { staff }\end{array}$ & $\begin{array}{c}\text { Technical } \\
\text { staff }\end{array}$ & Other & Total \\
Tuberculosis & $1(1)$ & 1 & $14(2)$ & 2 & $18(3)$ \\
Hepatitis & $2(1)$ & 1 & $27(2)$ & 5 & $35(3)$ \\
Shigellosis & 1 & $3(1)$ & $29(7)$ & 4 & $37(8)$ \\
Brucellosis & - & - & 1 & - & 1 \\
Figures for Scotland are in parentheses. & & &
\end{tabular}

those due to mouth pipetting. The most common injuries among all groups of laboratory workers were lacerations, splashes and burns to the hands or eyes, most of them relatively trivial.

The remaining phase of the investigation was a retrospective study of mortality among 156 pathologists (dying between 1955 and 1973) and 154 medical laboratory technicians (dying between 1963 and 1973) (Harrington, J. M. \& Shannon, H. S. Brit. med. J. 4,329 ; 1975). Both populations experienced lower mortality than the general population, as would be expected because any occupational group is likely to be healthier than the whole population.

The only examples of higher incidence among the laboratory populations were for lymphoma and leukaemia, which killed eight male English pathologists compared with the expected 3.3, and suicide which in England and Wales was the cause of death in nine male pathologists, compared with the expected 3.4, and nine male and six female technicians, compared with the expected 4.7 and 1.5 , respectively. Suicide proved to be the commonest cause of death among English female technicians. Their easy access to poisonous chemicals was thought to be the most likely explanation.

\section{Category A laboratories}

Laboratories approved by the Dangerous Pathogens Advisory Group to hold specific Category A pathogens, (in parentheses) as at December 12, 1978.

Department of Microbiology University of Reading (Rabies)

Central Public Health Laboratory Colindale (Rabies)

Central Veterinary Laboratory

Weybridge, Surrey (Rabies)

Evans Biologists Ltd

Liverpool (Rabies)

Animal Virus Research Institute Pirbright (Rabies)

Lister Institute

Elstree (Rabies)

Institute of Virology

University of Glasgow (Rabies)

Microbiological Research Establishment

Porton, Wilts. (Rabies, Lassa fever,

Marburg, Simian herpes B, Crimean

haemorrhagic fever (Congo),

Venezuelan equine encephalitis, Ebola)

London School of Hygiene and

Tropical Medicine

Winches Farm, St Albans (Crimean

hacmorrhagic fever (Congo), Venezuelan equine encephalitis)

Department of Virology

St Mary's Hospital Medical School London (Smallpox)

Wellcome Research Laboratories Ltd Beckenham, Kent (Rabies) 